\title{
Uppermost mantle P wavespeed structure beneath eastern China and its surroundings
}

\author{
Weijia Sun ${ }^{\mathrm{a}}$, B.L.N. Kennett ${ }^{\mathrm{b}}$ \\ ${ }^{a}$ Key Laboratory of Earth and Planetary Physics, Institute of Geology and Geophysics, \\ Chinese Academy of Sciences, Beijing 100029, China. \\ ${ }^{b}$ Research School of Earth Sciences, The Australian National University, Canberra, \\ ACT 2601, Australia.
}

\begin{abstract}
Pn travel-time tomography provides a way of improving structural information on the uppermost mantle across eastern China exploiting recent developments of dense seismic networks with well recorded seismic events. We used waveforms from 2009 at Chinese stations, supplemented by bulletin arrival times. An initial $\mathrm{P}$ wave model was constructed using the crustal model from CRUST1.0 coupled to a P wave model in the mantle derived from the SL2013sv model to capture the broad-scale features. This starting model enables us to compensate for the large contrasts in crustal thickness across the region. All events were relocated using the initial 3-D $\mathrm{P}$ model, and after relocation, consistent patterns of travel-time residuals are obtained. We extract $\mathrm{Pn}$ as the first arrival in the distance range $1.8^{\circ}$ to $12^{\circ}$. We use the FMTOMO (Fast Marching TOMOgraphy) approach to invert the travel-time results to generate a $\mathrm{P}$ wavespeed structure with a resolution of $2^{\circ} \times 2^{\circ}$ down to $75 \mathrm{~km}$. There are considerable variations in $\mathrm{Pn}$ wavespeed in the uppermost mantle across the region. The central portion of the North China craton is imaged with particularly slow $\mathrm{P}$ wavespeeds, whilst most of the neighbouring Ordos block is fast. Fast $\mathrm{P}$ wavespeeds extend through much of the uppermost mantle beneath eastern Central Asia Orogen, northeast China and beneath the Korean peninsula. In the south, the Sichuan Block and the western Yangtze craton show rather fast $\mathrm{P}$ wavespeeds. The Tanlu fault system appears to cut through the crust into the mantle with marked slow $\mathrm{P}$ wavespeed at its southern end.
\end{abstract}

Key words: Pn tomography, Uppermost mantle, Cratons, eastern China 


\section{Introduction}

We examine the $\mathrm{P}$ wavespeed structure in the uppermost mantle under eastern Asia (Figure 1) by exploiting a dense distribution of crossing paths for the epicentral distance range from $1.8-12^{\circ}$ for which the Pn phase refracted back from the uppermost mantle appears as a first arrival. For shorter distances the propagation of the onset of Pn samples the zone just beneath the Moho, but as epicentral distance increases the diving waves penetrate deeper and thus allow access to the whole zone down to $80 \mathrm{~km}$ that is poorly sampled by other means.

\subsection{East Asian tectonics}

The major tectonic elements in our study region (Figure $1 \mathrm{~b}$ ) are the southernmost part of the Siberian Craton, the North China Craton (NCC) and the South China Block, which are separated from each other by fold belts and orogens. The Siberian Craton, to the north, is mostly covered by Archean units and includes Paleoproterozoic foldbelts that were incorporated into the craton after 300Ma evolution (Glebovitsky et al., 2008). The North China Craton (NCC) is separated from the Siberian Craton by the Paleozoic-to-Mesozoic-age central Asian fold belt. The NCC was formed in the early Precambrian. The eastern part of the NCC underwent lithospheric thinning during the Mesozoic, which is commonly attributed to the impact of westward subduction of the Pacific Plate (e.g., Zhu and Zheng, 2009; Zheng et al., 2013). In contrast, the western part of the NCC retains full cratonic properties with a thicker lithosphere. The Qinling-Dabie orogen with outcrops of ultra-high pressure (UHP) metamorphic rocks was formed as the result of collisions between the NCC and the South China Blocks after the closure of the Shangdan Ocean and Mianlüe Ocean in the Middle Paleozoic (Li et al., 2007; Dong et al., 2012). In the southernmost part, the South China Block comprises the Yangtze Craton and the Cathaysia fold belt.

\subsection{Exploitation of Pn arrivals}

The main tool for investigating the $\mathrm{P}$ wavespeed of the uppermost mantle comes from the travel times of the Pn phase. The Pn arrivals are transmitted through the crust beneath the source, dive into the uppermost mantle

Email addresses: swj@mail.iggcas.ac.cn (Weijia Sun), Brian.Kennett@anu.edu.au (B.L.N. Kennett) 

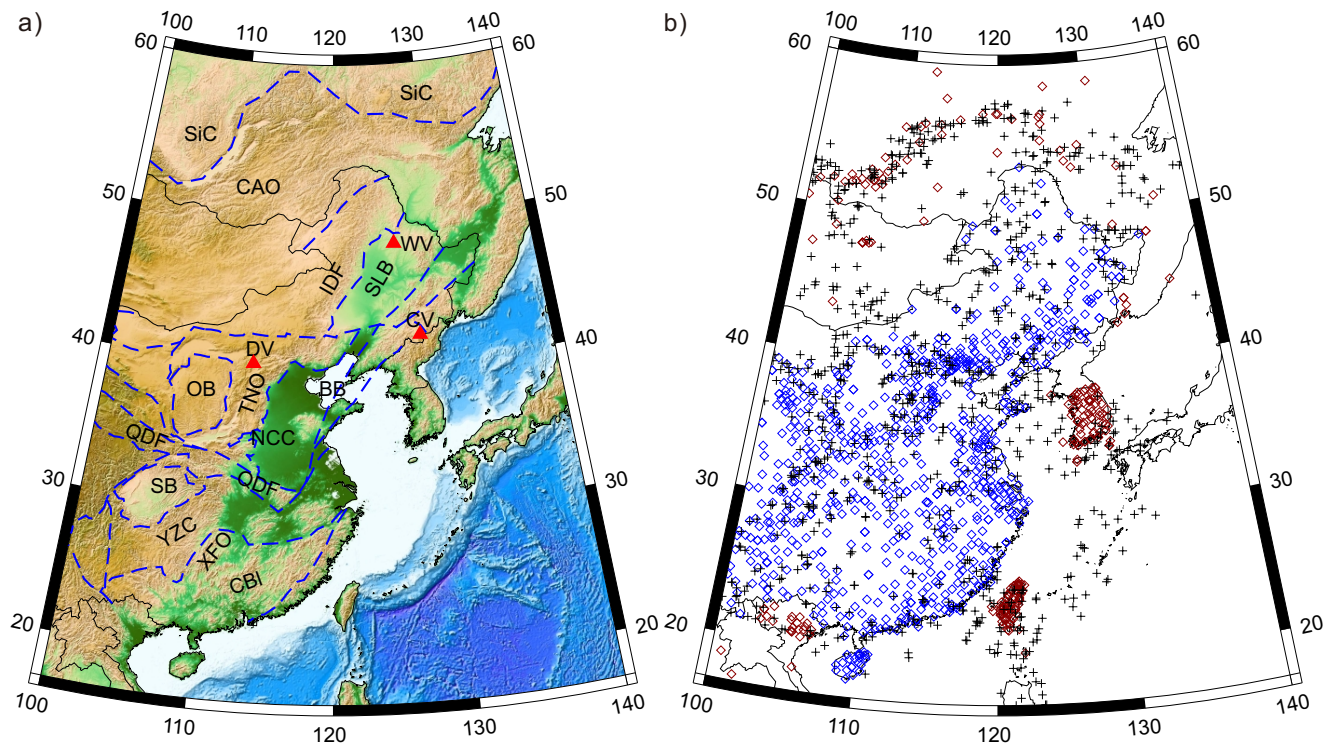

Figure 1: (a) The main tectonic units with boundaries indicated with dashed lines. Key to marked features: BB - Bohai Basin, CAO - Central Asian Orogen, CBl - Cathaysia Block, IDF - Inner Mongolia and Daxinganling Fold Belt, NCC - North China Craton, OB Ordos Basin, QDF - Qinling-Dabie Fold, SB - Sichuan Basin, SiC - Siberia Craton, SLB Songliao Basin, TNO - Trans-North China Orogen, XFO - Xuefeng-jiuling Orogen, YZC Yangtze Craton. The related volcanoes are marked by red triangles: CV - Changbaishan Volcano, DV - Datong Volcano and WV - Wudalianchi Volcano. (b)Location of seismic stations (diamonds) and events (black plus). Stations from Chinese Digital Seismic Network are shown in blue and those for which readings are taken from the ISC are shown in dark red. 
and are then refracted back to the free surface, passing again through the crust on the receiver side. For normal crustal thickness Pn is the first arrival beyond $200 \mathrm{~km}$. The Pn phase is of importance for location of earthquakes at regional distances. The travel times reflect variations in structure at the top of the lithospheric mantle, with penetration as deep as $85 \mathrm{~km}$ depending on the epicentral distance and the nature of the velocity gradients with depth. Pn travel time inversion provides the strongest velocity constraints in the uppermost mantle where other methods, e.g., teleseismic tomography with near vertical propagation provide more patchy coverage.

A number of authors have used Pn arrival information to examine structure just beneath the Moho beneath China (e.g., Hearn et al., 2004; Liang et al., 2004; Pei et al., 2007; Sun and Toksoz, 2006). Wang et al. (2013b) conducted tomographic inversion of Pn travel times for the East Asian region. Some authors have concentrated on the Pn velocities in specific regions, such as North China Craton (Li et al., 2011; Wang et al., 2013a), South China Sea (Xu et al., 2007), Yellow Sea (Xu et al., 2008), Korean and its surroundings (Hong and Kang, 2009).

Recently, inversions of Pn travel times have been performed with simultaneous anisotropy analysis (e.g., Liang et al., 2004; Pei et al., 2007; Buehler and Shearer, 2014) taking the mantle strain history or dynamic implications into account. In general, the introduction of anisotropy in the inversions tends to smooth the heterogeneities of Pn velocities, but there are some exceptions. The inclusion of $\mathrm{P}$ wave anisotropy led to more pronounced anomalies for Pn velocities beneath the Sierra Nevada in the western United States (Buehler and Shearer, 2014). In China, strong anisotropy is mainly found in the western regions beneath the Tibetan Plateau and the Tian Shan with recent large deformation, while anisotropy is quite weak in eastern China (Liang et al., 2004; Wang et al., 2013b). Here, we focus on the uppermost mantle Pn wavespeed beneath eastern China and its surroundings without consideration of anisotropy, since the patterns of travel-time residuals show no distinct grain.

In this study, we consider a broad region in east Asia and use events from 2009 to present. These recent events are mostly recorded by much more dense networks of permanent stations than in earlier work. Since 2008 the average distance between stations in eastern China is approximately 100 $\mathrm{km}$. The denser seismic configuration means that more stations record every event, and the influence of location errors is thereby diminished. 


\section{Data}

We mainly concentrate on the continental region of eastern Asia, including the eastern Chinese mainland, the Korean peninsula, eastern Mongolia and part of Siberia. This region is illustrated in Figure 1a. The locations of the seismic events and stations used are presented in Figure 1b. Earthquake clusters are observed in a number of regions, e.g., west of the Sichuan Basin, south of the Siberian Craton and around Taiwan. To achieve a uniform distribution of events, we grid the region into $1^{\circ} \times 1^{\circ}$ cells, and select the two events in each cell with the largest number of arrivals.

We have used Pn arrival times reported to the China Earthquake Data Center (CEDC: http://data.earthquake.cn/) for events with magnitude greater than 3.0 recorded by the dense permanent stations network in China from January 2009 to October 2015. These readings have been supplemented with arrival times from the Bulletin of the International Seismological Centre (ISC: http://www.isc.ac.uk) from January 1990 to February 2013. All the events used are relocated with the initial 3-D velocity model, following the procedure of de Kool and Kennett (2014), so that we have a uniform travel-time database to be used in Pn tomography as shown in Figure 2.

Close to the source the crustal phase Pg is the first arrival. But, beyond $1.8^{\circ}$ epicentral distance, it is expected that $\mathrm{Pn}$ becomes the first arrival since the average Moho depth is about $33 \mathrm{~km}$ (Li et al., 2014). The diving Pn waves can exit from the base of thin lithosphere, leading to significant changes in the frequency spectrum when the epicentral distance is greater than $15^{\circ}$ even for thick lithosphere. The thin lithosphere in parts of eastern China (Hearn et al., 2008; Zhao et al., 2013) means that Pn is trapped in the lithosphere for epicentral distances less than $12^{\circ}$. We have therefore limited the epicentral distance for the exploitation of the Pn travel times to $1.8^{\circ}-12^{\circ}$ when inverting for the $\mathrm{P}$ velocity structure in the uppermost mantle. After relocation we only retain events for which the focal depths are $2 \mathrm{~km}$ shallower than the Moho depth. To avoid erroneous readings we exclude any paths for which Pn travel-time deviations are larger than $8 \mathrm{~s}$ relative to the ak135 model (Kennett et al., 1995).

The application of these data selection criteria gives a total of 11,755 Pn travel-time paths from 829 natural and quarry sources, as shown in Figure 1b. In Figure 2 we display the ray paths with color coding of the residuals of the Pn travel times relative to the global ak135 model for events with good quality relocations. Fast paths relative to ak135 are indicated in green, and slower ones in red. The relatively consistent green residuals 


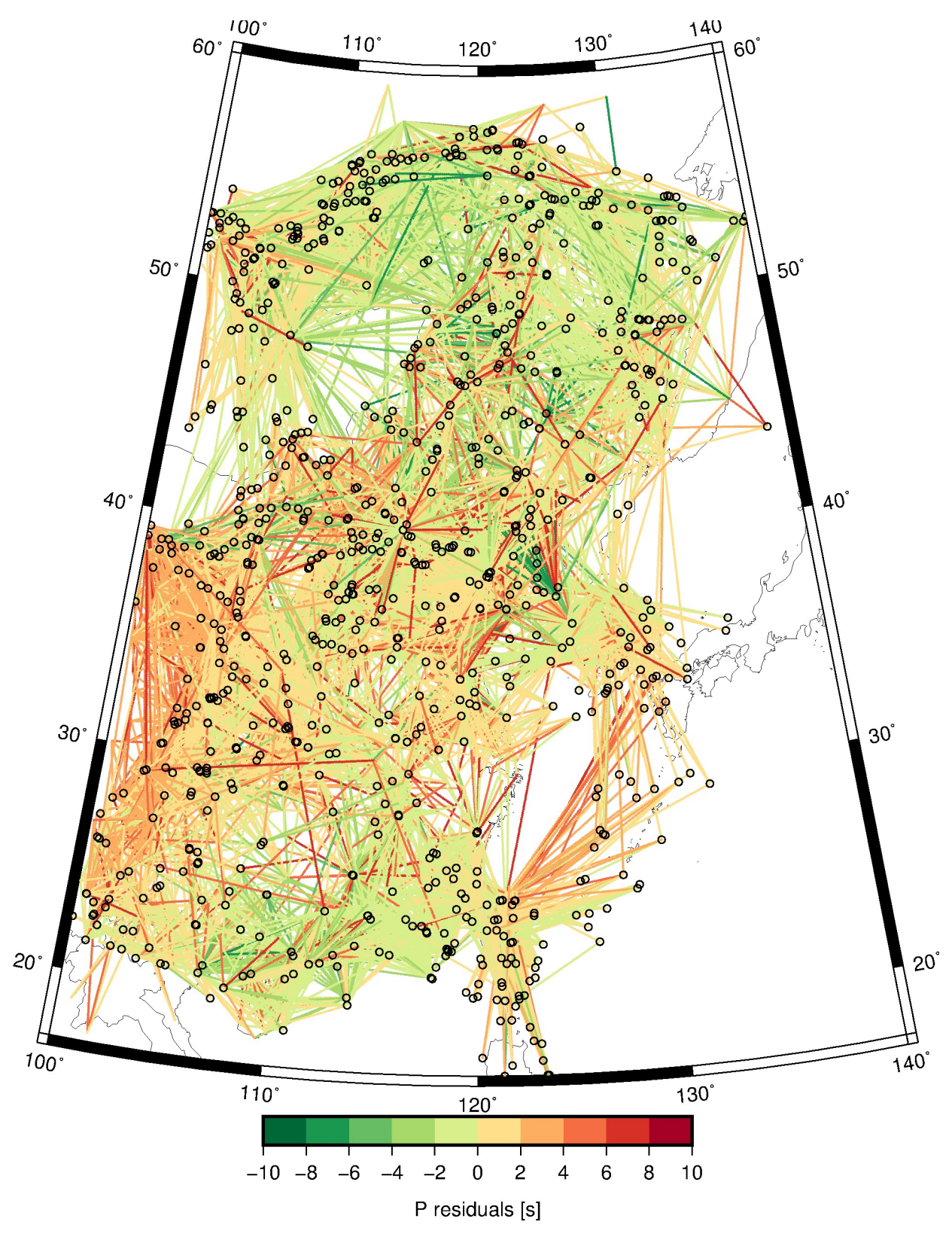

Figure 2: Pn wavepaths for well relocated events. The epicentres are marked by black circles. The paths are color coded by their $\mathrm{P}$ travel-time residuals relative to the 1D ak135 model (Kennett et al., 1995). Positive residuals indicate low velocities while negative correspond to high velocities. 


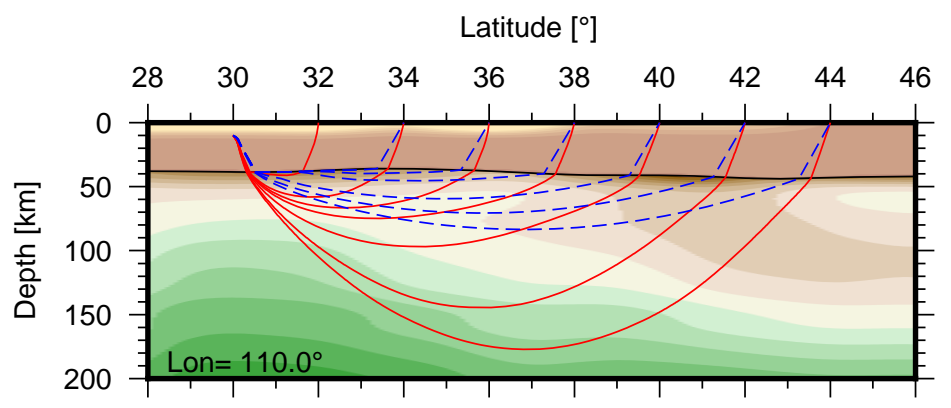

Figure 3: Comparison of Pn wavepaths in the 1-D ak135 model (blue dashed lines) and the initial 3-D P model (red solid lines) derived from the SL2013sv model. The source is located at $\left(110^{\circ} \mathrm{E}, 30^{\circ} \mathrm{N}\right)$ at a depth of $10 \mathrm{~km}$. Seven receivers are placed along longitude $110^{\circ} \mathrm{E}$ with epicentral distances ranging from $2^{\circ}$ to $14^{\circ}$ at intervals of $2^{\circ}$, so that the source and the receivers are located in the plane of a great circle.

in the northern region reflect the very fast wavespeed in the uppermost mantle. The significant positive (red) residuals in the westernmost region in the latitude range from $24^{\circ} \mathrm{N}-40^{\circ} \mathrm{N}$ is related to the thicker crust in this zone with the Moho lying as deep as $60 \mathrm{~km}$. The rapid variations in the residual patterns in the central and southern region suggests the presence of strong velocity differences in the shallow and deeper parts of the uppermost mantle.

Figure 3 compares Pn wavepaths in the 1-D ak135 model and our initial 3-D model derived from the SL2013sv model discussed in the followed section. The ray paths are calculated by the FMTOMO procedure, which is also used for predicting Pn travel times. Figure 3 shows that the Pn phases dive much deeper in a 3-D model than in the 1-D model, because of the differing velocity gradients. In the $1-\mathrm{D}$ model $\mathrm{Pn}$ runs right beneath the Moho for epicentral distances less than $6^{\circ}$, with slightly deeper penetration as the epicentral distance increases. In the 3-D model, the Pn paths can sample more deeply as a result of the lateral heterogeneities and the vertical velocity gradients of the Earth. Since the epicentral distances between events and stations are mostly between $2^{\circ}$ and $8^{\circ}$, the 3 -D imaging should have a good sampling down to $75 \mathrm{~km}$.

\section{Method}

\subsection{Initial $P$ velocity model}

Tomographic methods that depend on local linearisation with solution methods exploiting the gradients of the objective function are strongly de- 
pendent on the input velocity model used in the inversion. A good initial velocity model with small deviations from the true Earth model helps to accelerate the convergence rate, and more importantly avoids local minima of the misfit function. Good results are generally achieved using a relatively smooth initial model, with detail incorporated as the inversion proceeds when the Pn travel time information controls the structure.

In the absence of a 3-D reference model, a good procedure is to construct an initial $\mathrm{P}$ wave model in the mantle from an $\mathrm{S}$ wave model derived from surface wave tomography. Such models can give a good representation of the tectonic and geologic settings for long spatial-wavelengths. We have used the SL2013sv model of Schaeffer and Lebedev (2013), which was inverted exploiting the waveforms of surface waves and $\mathrm{S}$ body waves. This model provides uniform resolution across our study region. We convert the SV wavespeeds to a P model by using the procedure developed by Kennett et al. (2013) for the mantle component of the Australian Seismological Reference Model (AuSREM). The SV wavespeed deviations from the ak135 model are calculated at each point on the grid and converted to $\mathrm{P}$ deviations using empirical relations for variations in the $\mathrm{Vp} / \mathrm{Vs}$ ratio in cratonic regions, based on the work of Kaiho and Kennett (2000). The absolute P-wave speed is then constructed from the $\mathrm{P}$-wave speed deviations and the ak135 velocities. We use the CRUST1.0 model (Laske et al., 2013) for the initial $\mathrm{P}$ velocity model in the crust, and the depth of the Moho discontinuity.

\subsection{Event relocation}

We have relocated all the events used in the Pn tomography so that all locations are based on a common procedure, and do not depend on local 1-D models. To take account of the main 3-D variations we have relocated using the initial $\mathrm{P}$ wavespeed model using the nonlinear approach of de Kool and Kennett (2014). This locator employs the Neighbourhood Algorithm (NA) (Sambridge and Kennett, 2001) for the inversion, with pre-computed seismic travel times for all stations using the multi-stage fast marching method (FMM) and wavefield reciprocal theory, for a dense grid of sources. The multi-stage FMM is implemented in spherical coordinates, and can predict the travel times very accurately at the continental scale. During the NA inversion the travel times of the regional phases are extracted for an arbitrary spatial location via interpolation. The hypocenter is located directly in 4-D, with rapid convergence of the NA procedure. Multiple starting seeds are used to ensure that convergence has been achieved to the global minimum of the misfit criterion, though trapping in local minima is 
very unusual. The fully nonlinear method minimises the trade-off between the focal depth and the origin time for an event.

The relocation used all available crustal and uppermost mantle phases including $\mathrm{Pg}, \mathrm{Pn}, \mathrm{Sg}$ and $\mathrm{Sn}$, so that both the location and depth for each event have been well determined. Events with location shift of more than $1^{\circ}$ after relocation are discarded. Such poor events are mostly located in the ocean or in places with very limited event-station azimuthal distributions.

\subsection{Inversion of Pn travel times}

The suite of $\mathrm{Pn}$ travel times have been inverted for a 3-D tomographic model using the FMTOMO scheme (Rawlinson and Urvoy, 2006). This computationally efficient and robust procedure employs multi-stage FMM to predict the travel times of the Pn phases, with a subspace inversion scheme to optimize the model parameters to minimize the misfit function. The approach is fully nonlinear with recalculation of travel times at each iteration in the updated 3-D model. FMTOMO is a comprehensive package, and is able to carry out travel time tomography over different classes of body wave datasets, including local and regional events and teleseismic events for both active and passive sources. The model parameters used by the tomography are defined on regular grids in spherical coordinates, which avoids the earth-flattening approximation and still provides accurate travel times. The FMTOMO scheme is thus very suitable for solving large tomographic problems at the continental scales.

\section{Inversion results}

The region selected for the Pn tomography ranges over 43 degrees in latitude $\left(17^{\circ} \mathrm{N}-60^{\circ} \mathrm{N}\right)$ and 40 degree in longitude $\left(100^{\circ} \mathrm{E}-140^{\circ} \mathrm{E}\right)$, covering eastern China, eastern Mongolia, the Korean peninsula and part of Siberia in Russia. We have used a computational grid interval of $0.25^{\circ}$ in both latitude and longitude for the FMTOMO scheme. The maximum depth of the model extends to $200 \mathrm{~km}$ with an interval of $10 \mathrm{~km}$. This yields a total of 584,913 nodes without counting the refined grids in the source region, which are used to increase the accuracy in complex media (de Kool et al., 2006). The grid sampling is consistent for all calculations, including resolution tests and inversions.

The source locations are constrained to those relocated with the initial 3D velocity model. Since the initial P model is carefully constructed from the SL2013sv model which incorporates the broad scale variations in structure, 

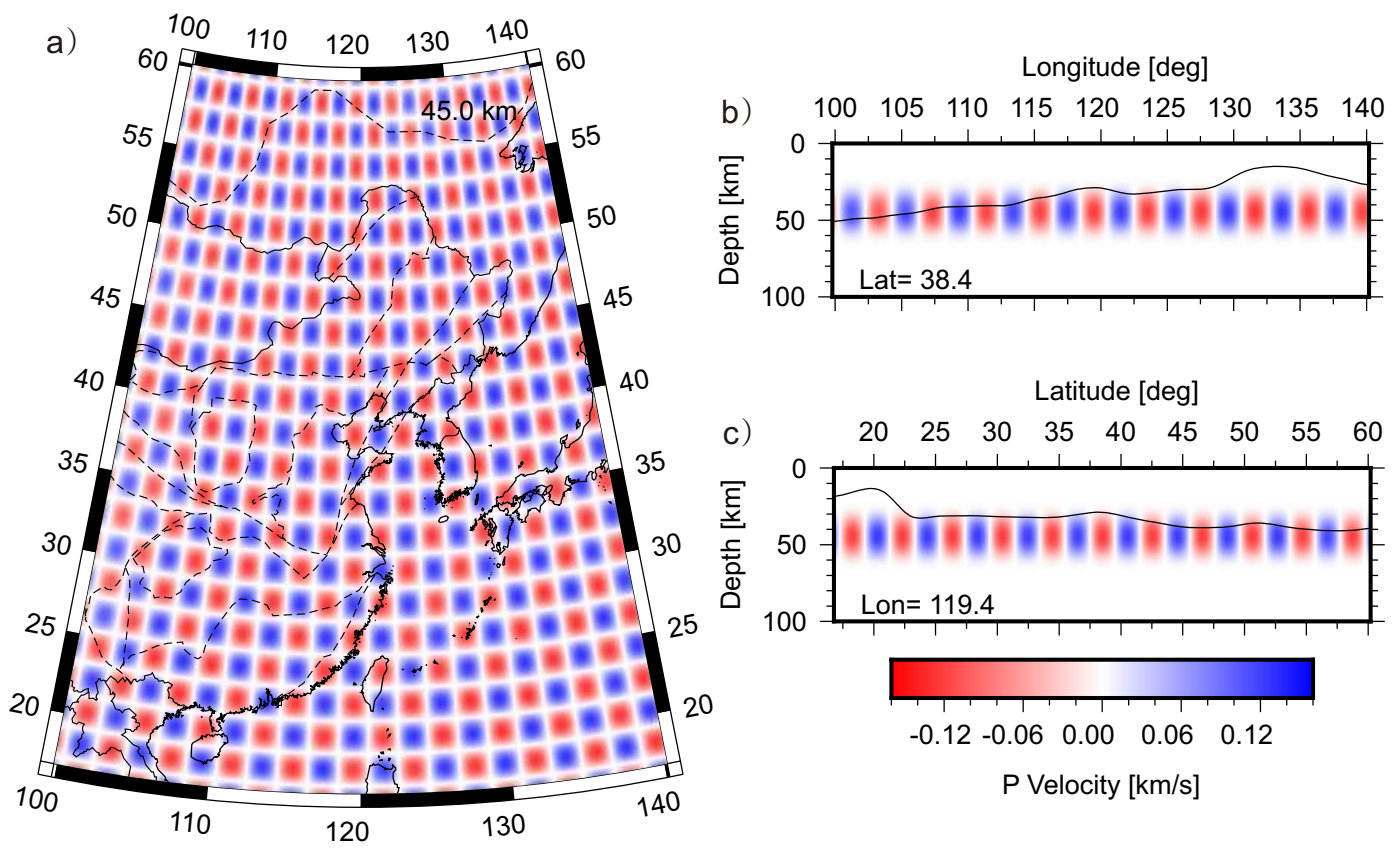

Figure 4: The input velocity model used for $2^{\circ} \times 2^{\circ}$ resolution test is shown with velocity deviations from the initial model for a heterogeneous layer centred at depth of $45 \mathrm{~km}$. (a) horizontal slices at depth of $45 \mathrm{~km}$ and (b)vertical slices at latitude of $38.4^{\circ}$ and (c) at longitude of $119.4^{\circ}$.

the inversion converged fast with rapid minimization of the misfit function. The variance of the Pn travel time residuals reduced $40 \%$, from those for the relocated events, after four iterations of the nonlinear inversion procedures.

\subsection{Resolution analysis}

The coverage of the available data can be qualitatively assessed from the ray path diagrams shown in Figure 2. Generally coverage is good, but there are a few patches where the distribution of sources and stations on the continent give a lower density of crossing paths. Coverage of the oceanic regions is sparse and so we do not consider these in our interpretation.

We can get a more quantitative assessment of the spatial resolution of our inversion, from checkerboard tests (Leveque et al., 1993) which examine the ability to discern small heterogeneous structures using the specific tomographic method and dataset. We first synthesize the travel time of regional Pn phases using the same configurations of source-event pairs and the velocity model with positive and negative velocity perturbation embedded on the background model. Then, the same inversion procedures as the real 


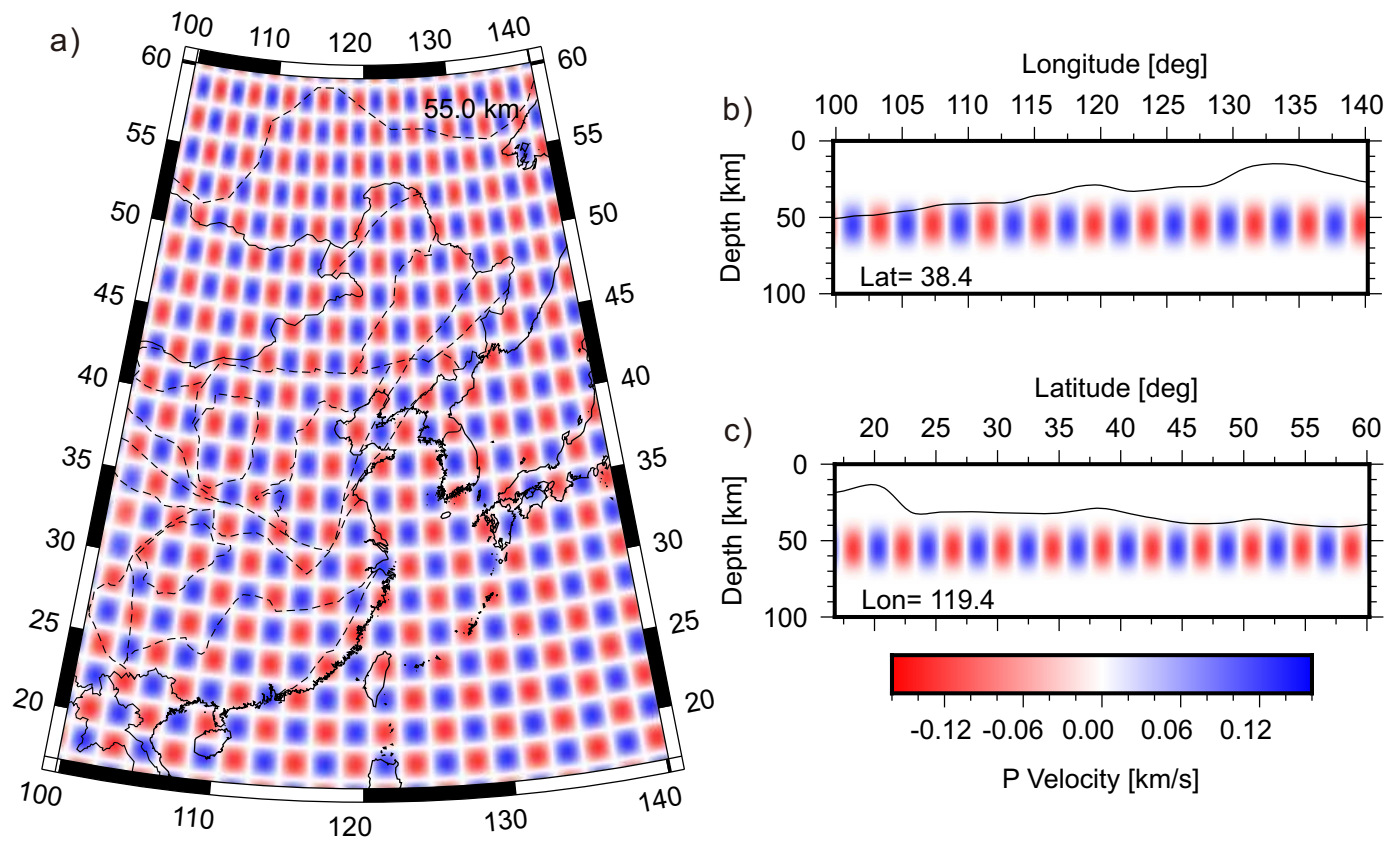

Figure 5: A similar test to Figure 4, but the heterogeneous layer now lies at depth of 55 $\mathrm{km}$ and the horizontal slice in (a) is taken at this depth.

dataset are performed to invert the synthetic dataset using the background model without velocity perturbations.

Due to the variations in depth of the Moho across the region and the vertical velocity gradient in the Earth, the regional arrivals dive into the mantle lid below the Moho discontinuities, rather than run just below the Moho interfaces as expected for a stratified medium. We employ a modified checkerboard pattern with a layer of heterogeneity immediately below the variable Moho interface, in preference to the traditional checkerboard with alternating fixed layers, which is still an unrealistic representation of Earth heterogeneities (e.g., Fichtner et al., 2009; Simmons et al., 2012). In these resolution tests, we considered two cases with heterogeneity confined to a flat layer with $2 \%$ negative and positive velocity anomalies centred at either 45 and $55 \mathrm{~km}$. The configurations are shown in Figures 4 and 5.

Figure 6 shows the recovered horizontal sections at depths of 45 and 55 $\mathrm{km}$ for each of the individual tests. The correspondingly vertical slices are shown in Figure 7 . The checkerboard patterns are generally recovered quite well with an imposed pattern at $2^{\circ} \times 2^{\circ}$ in both tests. The resolution in the region of eastern Mongolia centred at $111^{\circ} \mathrm{E}, 47^{\circ} \mathrm{N}$ tends to be a little 


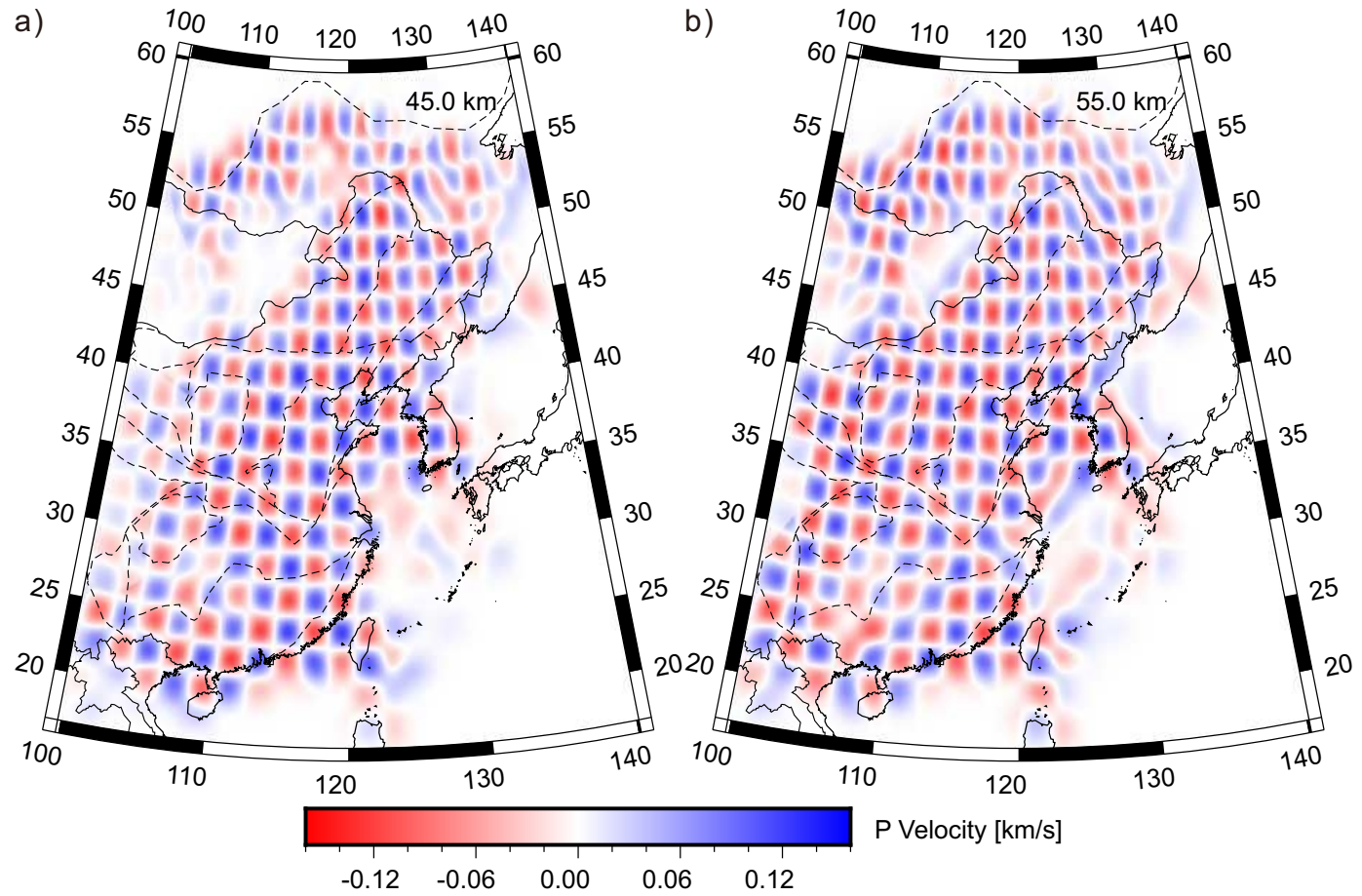

Figure 6: Results of the checkerboard resolution tests with horizontal slices at depth of $45 \mathrm{~km}$ (a) and $55 \mathrm{~km}$ (b) for the tests displayed in Figures 4a and 5a.

Longitude [deg]

Longitude [deg]

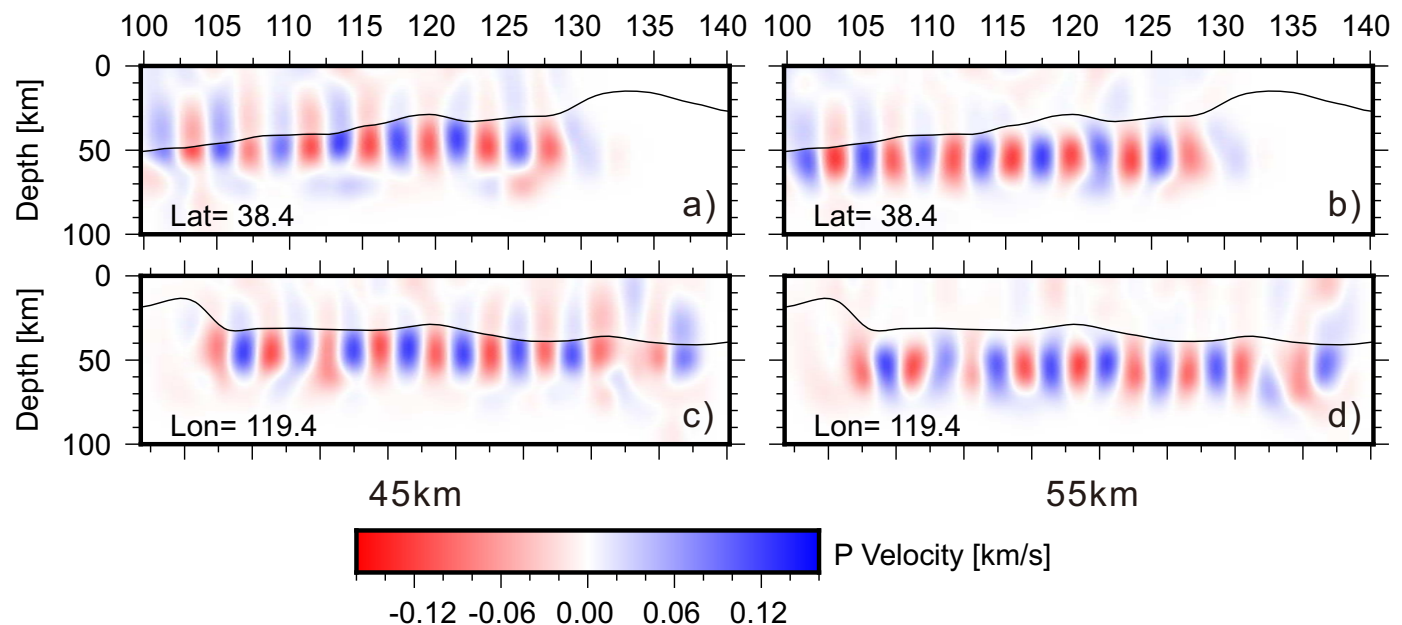

Figure 7: Results of the checkerboard resolution tests with vertical slices along latitude (a-b) and longitude (c-d). The left column shows vertical sections with the heterogeneous layer centred at $45 \mathrm{~km}$ while the right shows the ones with the layer centred at $55 \mathrm{~km}$. 
poor, due to limited numbers of events and stations located in this area. Weaker amplitudes of the recovered velocity anomalies are observed at the centre of $108^{\circ} \mathrm{E}, 24^{\circ} \mathrm{N}$, although the pattern of the checkerboard has been recovered well. This limited amplitude recovery is associated with only a few suitable earthquakes and a consequent difficulty in achieving sufficient crossing paths (see Figure 2).

Resolution around Beijing, the capital region of China, can be achieved at $1^{\circ} \times 1^{\circ}$ or finer, due to the very dense distributions of stations with an average spacing of $30 \mathrm{~km}$. However, the presence of the regularization, via the damping and smoothing factor, would smear the small heterogeneities, and also decrease the resolution. In addition, there is poor ray coverage due to very few earthquakes and stations in some areas like eastern Mongolia. Overall, we can expect good resolution at the $2^{\circ} \times 2^{\circ}$ scale for most of the continental regions.

The lower depth bounds of the imposed heterogeneity in the resolution tests in Figures 4(b-c) and 5(b-c) are placed at 65 and $75 \mathrm{~km}$. In both cases, the heterogeneous layers with velocity anomalies are well recovered including the bottom of the layers (see Figure 7), because of the sampling by the Pn wave diving below the Moho. The input checkerboard breaks in places through the Moho into the crust, and after inversion we find velocity perturbations in the crust with quite weak amplitudes as shown in Figure 4b. Although there is some sensitivity to the crust in Pn, this is much weaker than for the crustal Pg phase.

\subsection{3-D P wavespeed structure}

The current station distribution in China has enabled us to achieve a dense pattern of crossing paths for Pn in most locations, but we still need to invoke modest regularisation to the inversion. We employ a combination of weak damping and smoothing alongside the data fit in the objective function that is minimised. The damping term prevents too large a change in the wavespeed model at each iteration. Whereas, the smoothing term helps to reduce the effects of strong variations at local scale. The regularisation terms help to reduce the non-uniqueness in the inversion, but the choices have to be carefully made or the terms dominate the data fit and resolution is lost. Because of the presence of the regularisation the velocity anomalies from the inversion will generally be slightly smaller than the real ones (Kulakov, 2008).

From the FMTOMO inversion we develop 3-D models for both the crust and the uppermost mantle. Figures 8 and 9 illustrate the inverted 
$\mathrm{P}$ wavespeed at depths of 45, 55, 65 and $75 \mathrm{~km}$ with a comparison with the initial P velocity model constructed from the global 3-D SL2013sv model. We display the absolute velocities with the same scale ranging from $7.5 \mathrm{~km} / \mathrm{s}$ to $8.5 \mathrm{~km} / \mathrm{s}$ in all figures. The resolution tests above (Figure 6) indicate that the 3-D P wavespeed model should be reliable except in a couple of patches in eastern Mongolia and in the central western part of the Yangtze craton. The inverted model has similar broad characteristics to the input model as shown in Figures $9 \mathrm{~b}$ and $9 \mathrm{~d}$, but there are striking modifications to the $\mathrm{P}$ velocities in the North China Craton and eastern Mongolia. There is a general tendency for the inverted $\mathrm{P}$ wavespeed model derived from the Pn travel times to be faster than the initial model converted from the SV wavespeed model SL2013sv, with a sharpening of features that are already visible in the broad-scale initial model.

At $45 \mathrm{~km}$ depth many parts of eastern Asia have rather slow $\mathrm{P}$ wavespeed (Figure 8c) though there are scattered zones with higher $\mathrm{P}$ velocities in northeastern China, the southern Ordos Basin and the southern Cathaysia belt. In the Bohai Basin, the centre displays rather low velocity with much higher velocities in the surroundings. Fast $\mathrm{P}$ wavespeed is also found beneath most of the Korean Peninsula. The slowest $\mathrm{P}$ wavespeed at $45 \mathrm{~km}$ depth occurs at the centre of North China Craton (NCC), with boundaries that align very well with the craton margin. The other area with particularly low $\mathrm{P}$ velocity is at the start point $118^{\circ} \mathrm{E}, 32^{\circ} \mathrm{N}$ of the Tanlu Fault. The features with very low velocities at $45 \mathrm{~km}$ depth in Siberia and on the western margin of the inversion are linked to zones of thick crust, so that crustal velocities are encountered rather than those associated with the mantle.

The pattern of faster $\mathrm{P}$ wavespeeds are noticeably different at the depth of $55 \mathrm{~km}$ (Figure 8d) compared with those at $45 \mathrm{~km}$ depth, with now most areas having wavespeeds greater than $8.1 \mathrm{~km} / \mathrm{s}$. The lowest $\mathrm{P}$ velocities $(\leq 7.6 \mathrm{~km} / \mathrm{s})$ are still seen at the centre of the NCC and also at the corner of Qinglin-Dabie orogen and the southern end of the Tanlu fault. Similar features are also found at the depth of $65 \mathrm{~km}$ (Figure 9c). The highest $\mathrm{P}$ velocities $(\geq 8.2 \mathrm{~km} / \mathrm{s})$ are found in the regions of eastern Mongolia and northeastern China. In the NCC and Korean peninsula, fast and low P velocities are distributed in a mosaic form. The nucleus of the Yangtze Craton shows P wavespeeds faster than $8.2 \mathrm{~km} / \mathrm{s}$, including the Sichuan Basin. At $75 \mathrm{~km}$ there is a significant change in the wavespeed distribution with the faster $\mathrm{P}$ wavespeeds confined to the western part of the study region, and 

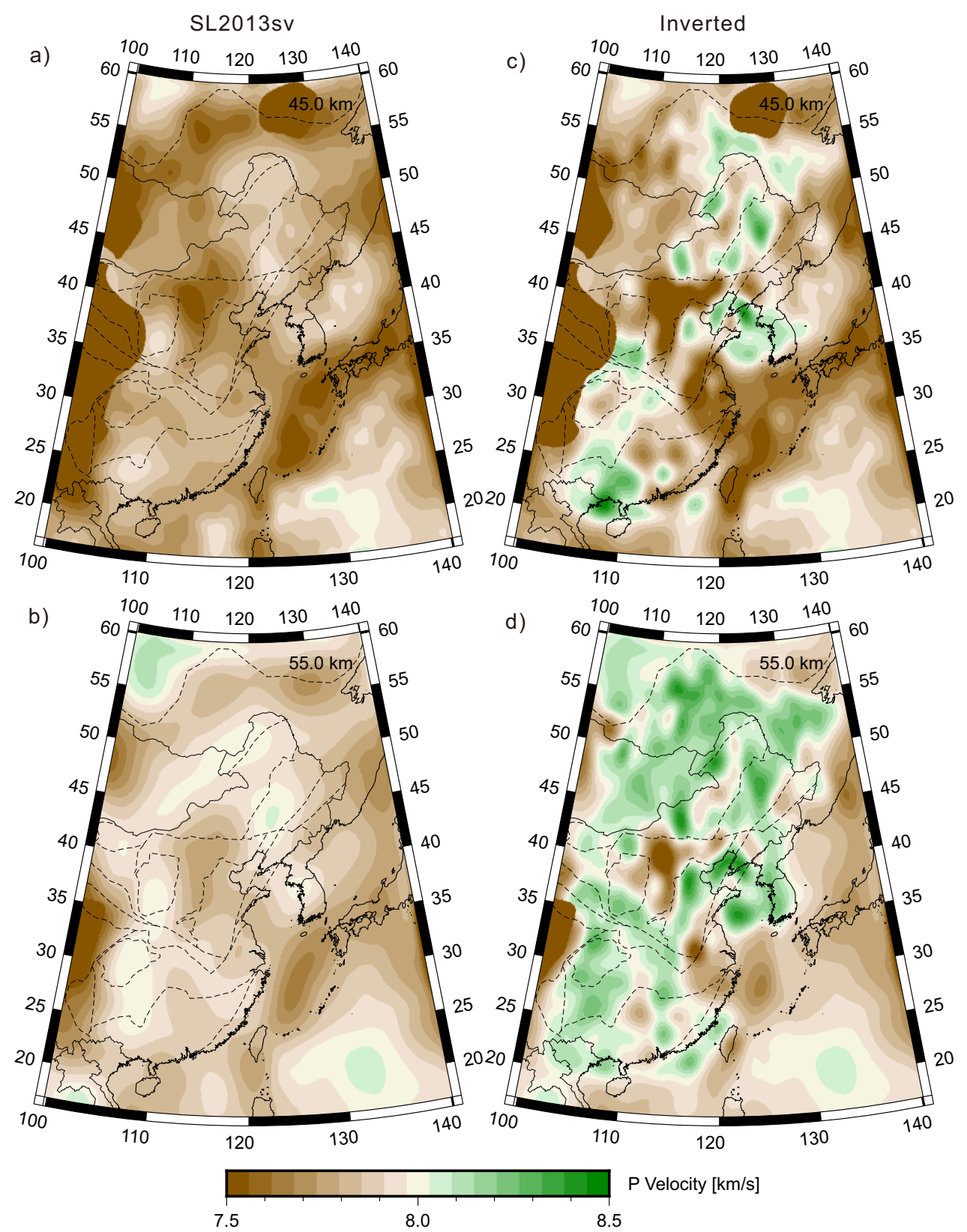

Figure 8: Sections through the Pn wavespeed at depths of 45 and $55 \mathrm{~km}$. The left column shows the initial P velocity model $(\mathrm{a}, \mathrm{b})$ built from the SL2013sv model, the right column presents the inverted model $(\mathrm{c}, \mathrm{d})$. The sections are displayed as absolute velocities. 

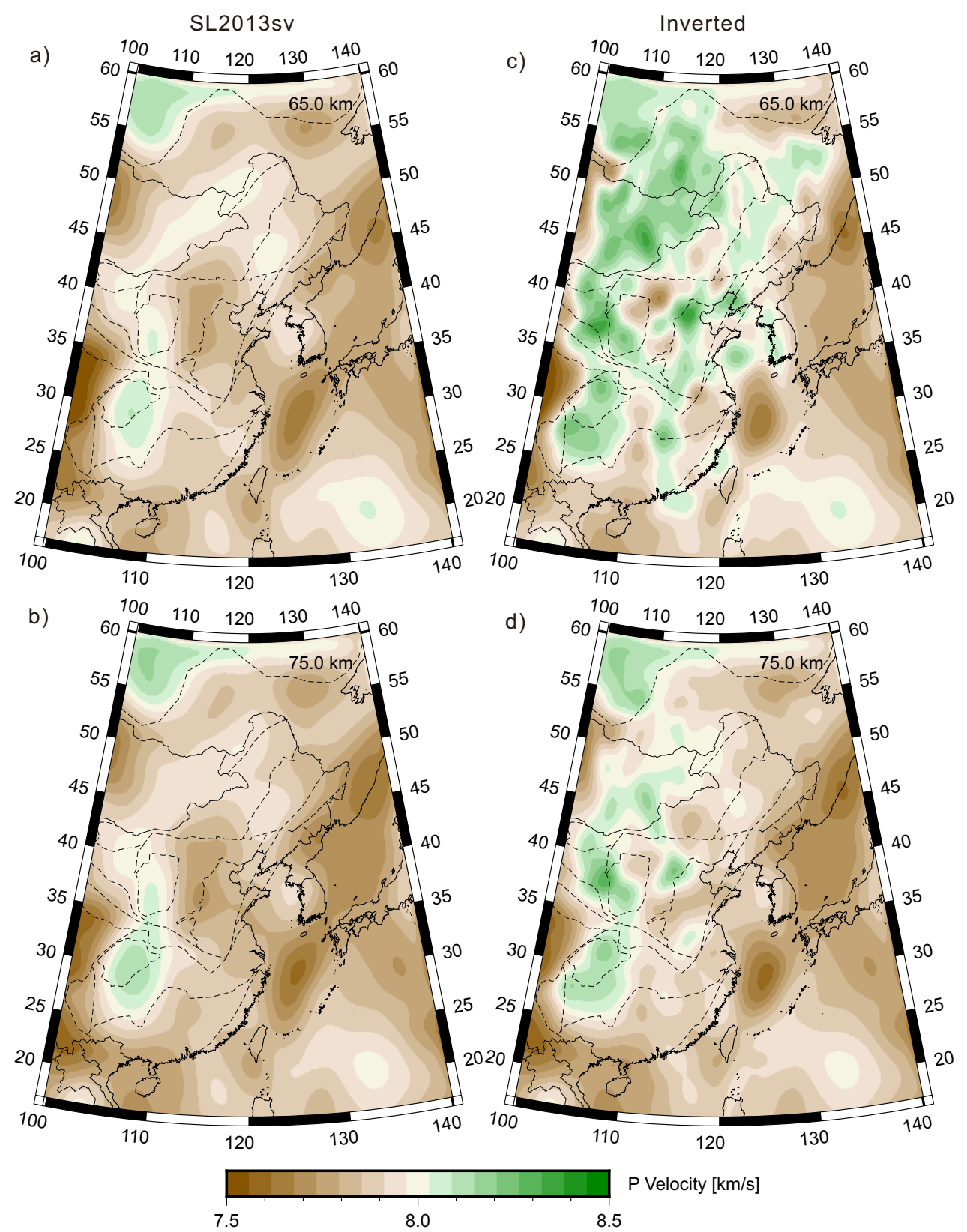

Figure 9: Sections through the Pn wavespeed at depths of 65 and $75 \mathrm{~km}$. The left column shows the initial P velocity model $(\mathrm{a}, \mathrm{b})$ built from the SL2013sv model, the right column presents the inverted model $(\mathrm{c}, \mathrm{d})$. The sections are displayed as absolute velocities. 
much less difference from the initial model. However, at this depth the ray path coverage is rather patchy and so resolution is only attainable at larger scale.

A notable slow zone is found at all depths beneath the East China Sea Basin centred at $124^{\circ} \mathrm{E}, 30^{\circ} \mathrm{N}$. This feature is largely inherited from the initial model, since there is very limited resolution from the Pn path coverage, so we do not interpret it.

Vertical sections through the inverted model are shown with slices at constant longitude in Figure 10 and at constant latitude in Figure 11. In each case we have used steps of $5^{\circ}$. We have employed separate color schemes for the crust and mantle wavespeeds to allow detail to be seen. The corresponding vertical slices for the initial model are shown in the Appendix in Figures A1 and A2.

Although the travel time residuals for the regional phase Pn are dominantly governed by the velocity structures of uppermost mantle, there is some sensitivity to crustal velocities near the source and receiver. As a result the inversion also updates the crustal velocities to some extent. We see in the vertical sections that the uppermost mantle $\mathrm{P}$ velocities generally tend to be higher after inversion than in the initial model. The exception where continental mantle $\mathrm{P}$ velocities are reduced after inversion is found for the section at latitude $40^{\circ} \mathrm{N}$ from $112^{\circ} \mathrm{E}-120^{\circ} \mathrm{E}$ (Figure 11), where comparison with the initial model shown in Figure A2 suggests that the crust may be thicker than in the CRUST1.0 model. This zone of thicker crust, most likely linked to the Trans-North China Orogen, appears to extend further south with a weak effect also at $35^{\circ} \mathrm{N}$.

Other areas where the inverted $\mathrm{P}$ wavespeed is lower than in the original model occur beneath the oceanic zones, where the path coverage is scarce. Such features are likely to arise from undue influence from a single path.

\section{Discussion}

The use of the diving Pn wave provides nearly horizontal sampling of the mantle between source and receiver and thus Pn tomography with high path density can achieve good definition of horizontal gradients in the uppermost mantle. The depth extent for which 3-D imaging can be achieved is no more than $75 \mathrm{~km}$, but high definition is provided just in the depth range where teleseismic tomography suffers most from ray-crowding and limited vertical

resolution. Because our inverted model is in the same form as the initial 


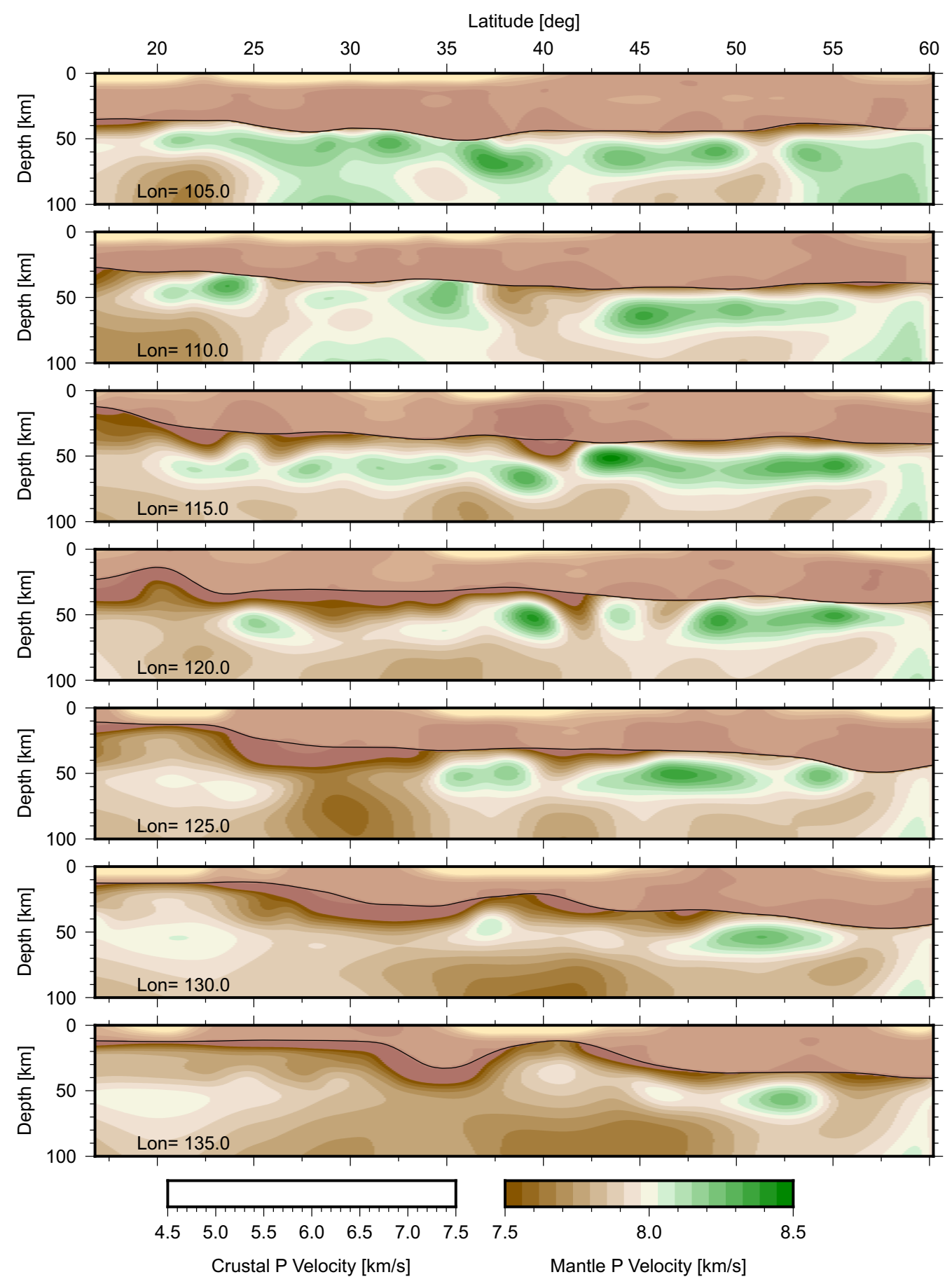

Figure 10: Sections through the inverted Pn wavespeed for longitudes between $105^{\circ} \mathrm{E}$ and $135^{\circ} \mathrm{E}$ in step of $5^{\circ}$. The sections are displayed as absolute velocities. Separate color schemes are used for the crust and mantle 18 allow detail to be seen. 


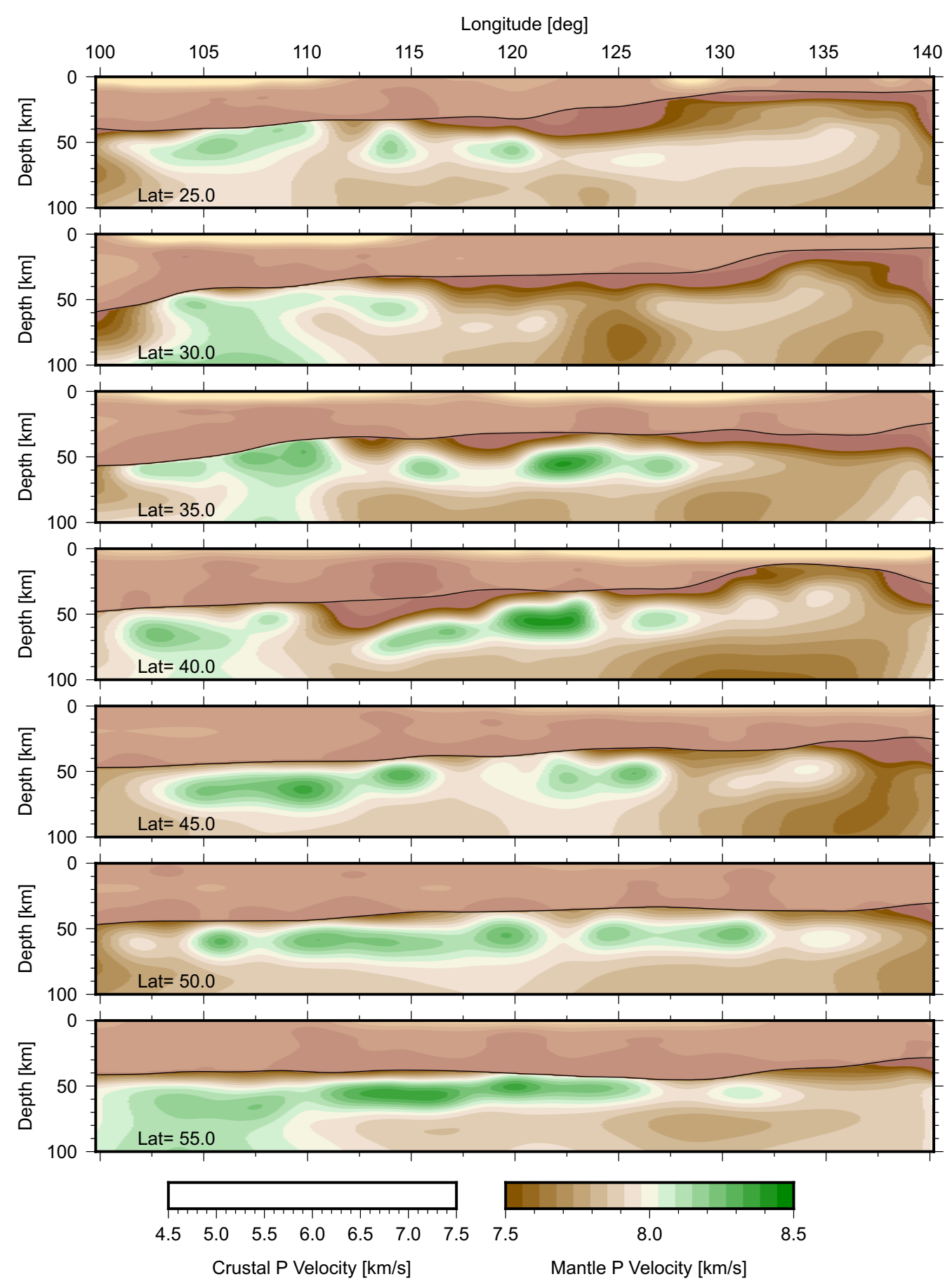

Figure 11: Sections through the inverted $\mathrm{Pn}$ wavespeed for latitudes between $25^{\circ} \mathrm{N}$ and $55^{\circ} \mathrm{N}$ in step of $5^{\circ}$. The sections are displayed as absolute velocities. Separate color schemes are used for the crust and mantle 19 allow detail to be seen. 
model it can again be used for event relocation in 3-D model and thus provide a further improvement in hypocentral parameters for east Asia.

\subsection{Reliability of inversion results}

For the east Asian region with a complex pattern of tectonic features, we significantly improve the effectiveness of the inversion of the Pn travel times by starting from a fully 3-D model. However, any initial model is likely to leave its imprint on the final results. We have therefore undertaken alternative inversions to check the stability of our results. In the Supplementary Material we present the results of inversion of the same suite of Pn arrival times, but now using the LITHO1.0 (Pasyanos et al., 2014) starting model for both event location and inversion. The crustal model CRUST1.0 is common to the two cases, but the mantle model in LITHO1.0 is derived from surface wave dispersion. There is a close correspondence in the resulting 3 -D P wavespeed models in the continental regions where we have good resolution. However, significant differences are present in the poorly resolved oceanic zones where the influence of the initial model is strongest.

The initial P model derived from SL2013sv shows major differences from the LITHO1.0 model in both the $\mathrm{P}$ wavespeed and its distribution. Nonetheless, the recovered structures from both initial models are very similar in the pattern of slow and fast $\mathrm{P}$ wavespeeds. The quantitative deviations among the two initial 3-D models and their correspondingly inverted models are presented in the Supplementary Material, and indicate the robustness of the tomographic results from the initial 3-D models.

We further investigate the reliability of the Pn inversion results by employing an initial model constructed from the 1-D ak135 model for the mantle component and the 3-D LITHOS1.0 model for the crustal component. This initial model includes just lateral and vertical variations in the crust, which reduces the influences of the crust on the waves propagation in the uppermost mantle. Figure 12 shows the inverted Pn velocities at depth of 45 and $55 \mathrm{~km}$ from the initial 1-D model for the mantle and the 3 -D crustal model. The distributions of slow or fast Pn wavespeeds at 45 $\mathrm{km}$ depth in Figure 12a are similar with those inverted from a fully initial 3-D model in Figure 8, but with weak amplitudes of velocity variations. However, the Pn wavespeeds at $55 \mathrm{~km}$ show a significantly faster pattern inherited from the initial model. This is because the Pn phases for most events with epicentral distances no larger than $8^{\circ}$ now only sample the part of uppermost mantle right beneath the Moho in the 1-D model (see Figure 3 ), without consideration of the strong lateral variations beneath eastern 


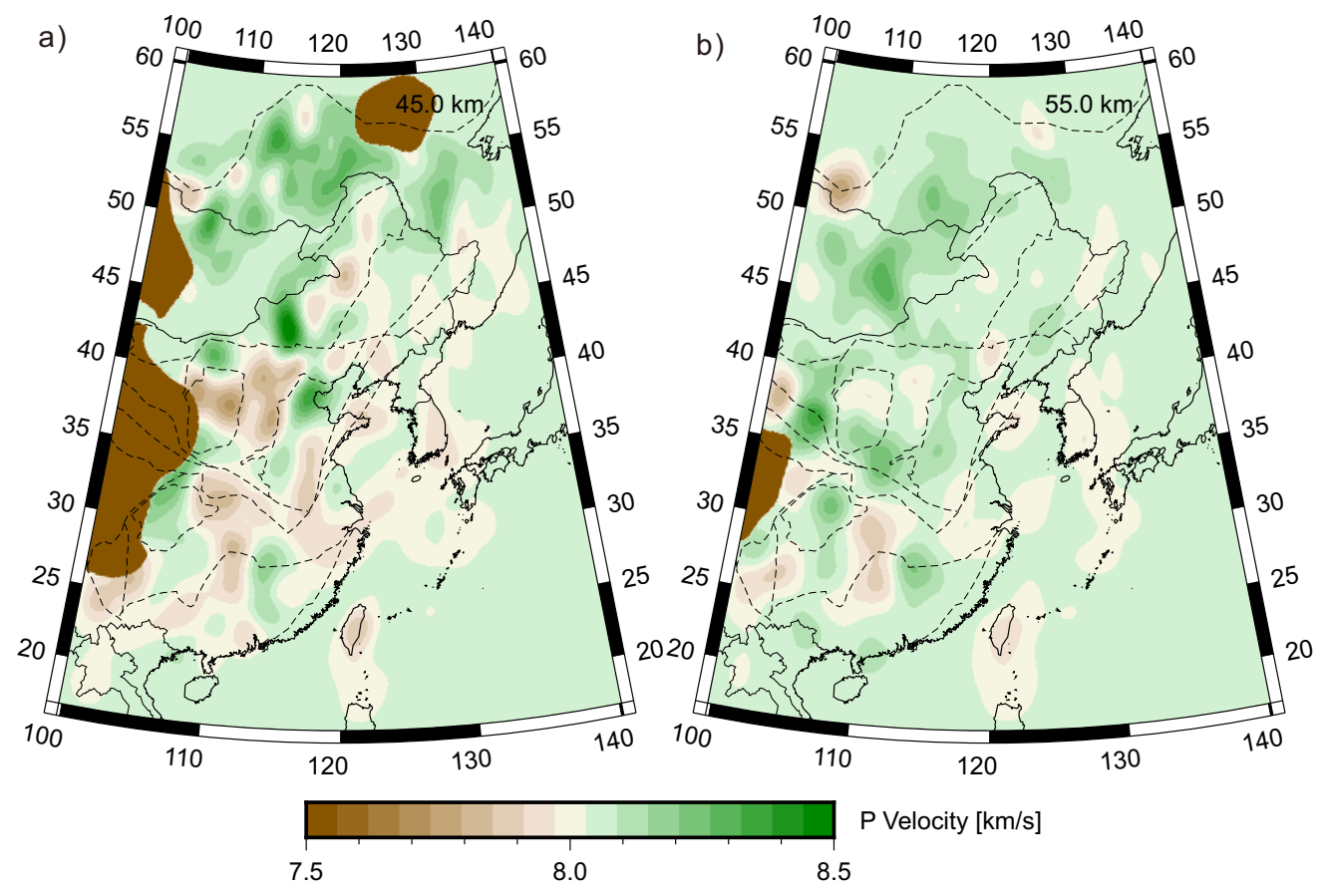

Figure 12: Sections through the inverted Pn velocities at depth of 45 (a) and $55 \mathrm{~km}$ (b) from the initial 1-D model $a k 135$ for the mantle and the 3-D crustal model. The sections are displayed as absolute velocities.

China. Consequently, Pn inversion from a fully 3-D initial model is much more reliable and robust than those from an initial 1-D model.

\subsection{Comparisons with previous studies}

Even with the generally dense network of stations in eastern China, teleseismic tomography studies exploiting $\mathrm{P}$ waves have found it hard to provide definition of the uppermost mantle. Thus, e.g., Zhao et al. (2012), concentrated attention on structures below $150 \mathrm{~km}$. For a portion of eastcentral China, Jiang et al. (2015) were able to achieve high-resolution and definition of structure from $50 \mathrm{~km}$ downwards. For the upper part of the mantle, surface wave tomography has provided most detail for shear wave structure (e.g., Panning et al., 2012; Legendre et al., 2014).

Here we concentrate on uppermost mantle structures using the largely horizontal propagation of Pn. Several authors have conducted the Pn tomography across the China continent (Hearn et al., 2004; Liang et al., 2004; Pei et al., 2007; Sun and Toksoz, 2006) and in surrounding region (Wang 
et al., 2013b), but most attention has been directed on mapping the average velocity distribution of the uppermost mantle, which may smear small heterogeneous velocity anomalies. We have been able to use more recent data since 2009 for which the rapid development of Chinese Digital Seismic Networks provide a denser station distribution with average station separation less than $100 \mathrm{~km}$ in eastern China. Further, we provide uppermost mantle velocity information as a function of depth, exploiting the way in which Pn paths dive deeper into the mantle as the epicentral distance increases due to the vertical velocity gradient (e.g., Ritzwoller et al., 2002).

Most of the previous authors reported that the mantle lid beneath eastern China has generally low velocities, which is what we see at the depth of $45 \mathrm{~km}$ immediately below the Moho (Figure 8c). The uppermost mantle $\mathrm{P}$ wavespeeds beneath the North China Craton are faster than in previous work (Hearn et al., 2004; Liang et al., 2004; Pei et al., 2007; Wang et al., 2013b) that exploited the method developed by Hearn et al. (2004). In these studies the resolution achieved in the east part of North China Craton and northeastern China was at best $3^{\circ} \times 3^{\circ}$, and often at larger scales. Thanks to additional data and a denser station distribution, our results achieve a higher resolution of $2^{\circ} \times 2^{\circ}$, or better, in these regions. Results from deep seismic sounding data (DSS) suggest very high $\mathrm{P}$ velocies (up to $8.2 \mathrm{~km} / \mathrm{s}$ ) in the uppermost mantle beneath the east part of North China Craton ( $\mathrm{Li}$ et al., 2006a), which is more consistent with our results than the earlier studies.

In a more specific regional study, Li et al. (2011) examined uppermost mantle structures of the North China Craton from Pn travel time tomography using the method of Hearn et al. (2004), with a comparable resolution of $2^{\circ} \times 1.6^{\circ}$ to our results. Li et al. (2011) reported prominent high Pn velocities in the eastern North China Craton and the Bohai Basin, which agrees well with our results in this area. For the same region similar velocity patterns were reported by Sun and Toksoz (2006). The differences between the different models largely arise from the relatively rapid changes in seismic wavespeed and reflect the varying capacity of the seismic data used in the different studies to discern smaller heterogeneous features.

\subsection{Eastern Central Asian Orogen and northeastern China}

The eastern Central Asian Orogen, bounded by the Siberian Craton and the North China Craton, shows very fast Pn wavespeed. So far, little attention has been given to the eastern Central Asian Orogen, which 
might well be due to the hostile climate conditions and difficulties for access. These issues have limited deployments of dense sets of seismic stations, which are generally used by traditional tomographic schemes (Koulakov and Bushenkova, 2010).

A number of body wave tomography studies include or partly include this region. Ritzwoller et al. (2002) determined the uppermost mantle velocities across the Eurasian continent, their results presented high Pn velocities in the region, but without interpretation, since they concentrated on improving location capabilities. Kulakov (2008) reported similar results with fast $\mathrm{P}$ wavespeeds at $50 \mathrm{~km}$ depth, which covered part of the region. Again little interpretation was provided since the focus of attention was on the possible mantle plume in Siberian Craton and central Mongolia. Recently, Wang et al. (2013b) presented relatively high Pn velocities in this region but with poor resolution.

With a combination of geological and geophysical data, Didenko et al. (2010) have systematically studied the lithosphere structures in the eastern Central Asian Orogen, which is composed of several Precambrian continental blocks (see Figure 1 of Didenko et al. (2010)). These Precambrian micro-continents, e.g., Argun-Mamyn, Dyagdachi, and Bureya, correlate well with the fast Pn anomalies we have found in this region. In addition, quite a few earthquakes have occurred during the last few decades (see Figure 1b), which indicates continuing deformation in the region. The events tend to concentrate at the edge of the high Pn velocities that may well be linked to ancient and stable craton-like tectonic units.

The low mantle velocities below northeastern China relative to its surrounding areas might be attributed to high temperatures (Didenko et al., 2010). The NECESSArray (NorthEast China Extended SeiSmic Array) project, an international collaboration between China, Japan and the USA, deployed 127 portable stations in northeastern China, and this dataset has been used for joint inversion receiver function and ambient noise studies (Guo et al., 2015) and also for Lg attenuation (Ranasinghe et al., 2015). Low velocities features in the crust may be further linked to the presence of volcanic activities (e.g., Lei and Zhao, 2005; Guo et al., 2015). Teleseismic body wave tomography (Tang et al., 2014) suggests high $\mathrm{P}$ velocities beneath the Songliao Basin extend downward to a depth of $300 \mathrm{~km}$ or more, which might indicate cooling lithosphere (Tang et al., 2014) compared with mantle upwelling related to active volcanic activities in other parts of northeastern China and dense mantle suggested by gravity anomalies (e.g., Suo 
et al., 2015).

\subsection{North China Craton}

A prominent slow $\mathrm{P}$ wavespeed anomaly in the centre of the North China Craton is found in the uppermost mantle in our inversion. This is bounded by the eastern margin of Ordos Basin in the west and Trans-North China Orogen in the east. A similar feature has been reported by teleseismic body wave tomography (e.g., Tian et al., 2009; Lei, 2012) and regional Pn tomography (e.g., Li et al., 2011; Wang et al., 2013a). The low velocity zone is visible in the crust (Wang et al., 2013a), while the body wave tomography results from teleseismic events suggest that it may extend downward to around $300 \mathrm{~km}$ (Tian et al., 2009; Lei, 2012), though this could include some component of vertical smearing. The reduced velocities have been attributed to magmatic activities during late Mesozoic and Cenozoic, around the inactive Datong volcano. We note that the extent of the slower wavespeed region at $45 \mathrm{~km}$ has a close correspondence with the tectonic boundaries, but this is less pronounced at depth.

The Ordos basin is considered to be the well preserved nucleus of the North China Craton, much of which experienced lithospheric thinning and destruction during the Mesozoic (e.g., Zhu and Zheng, 2009; Zheng et al., 2013). The uppermost mantle beneath most of the Ordos Basin shows high $\mathrm{P}$ velocities characteristic of a stable and old craton. Yet, a small zone beneath the northeast Ordos basin shows consistently low velocity, which is a little difficult to interpret. The differences beneath the northern and southern part of Ordos Basin can also be seen in the Pn tomographic images by Wang et al. (2013b). These lowered velocities may be linked to hot upwelling materials associated with westward subduction of the PaleoPacific Plate in the Mesozoic (e.g., Dong et al., 2014), and rifting of the eastern North China Craton along its western margin inthe Paleoproterozoic (e.g., Zhao et al., 2009; Li et al., 2010).

In our model, the uppermost mantle beneath the Bohai Basin shows both high and slow $\mathrm{P}$ wavespeed, with a slow central core surrounded by faster material. Previous lower resolution Pn tomography suggests slow Pn wavespeed across the entire Bohai Basin (e.g., Hearn et al., 2004; Pei et al., 2007). But, our results are strongly supported by body wave tomography with regional events ( $\mathrm{Xu}$ et al., 2008) and combinations of local, regional and teleseismic events (Li et al., 2006b; Huang and Zhao, 2009) at the local scale. 
A prominent low velocity feature is imaged at the southern part of Tanlu Fault, which runs for about 2,400 km through eastern China. The low velocity in the mantle beneath the Tanlu Fault indicates that the Tanlu Fault cuts through the full crust and Moho, and extends into the uppermost mantle, which would be consistent with deep seismic sounding data (Liu et al., 2015). As the depth increases from 45 to $65 \mathrm{~km}$, the low velocity zone along the Tanlu Fault $\left(32^{\circ} \mathrm{N}-38^{\circ} \mathrm{N}\right)$ gradually shrinks to the southern part of Tanlu Fault $\left(118^{\circ} \mathrm{E}, 32^{\circ} \mathrm{N}\right)$. This suggests that Tanlu Fault system penetrates deeper in the south than in the north.

The recent study by Jiang et al. (2015) in east-central China using locally dense networks indicates presence of significant contrasts in structure in the uppermost mantle. Along $34^{\circ} \mathrm{N}$ they also see the contrast between near coastal high velocities and lower velocities in the west .

\subsection{South China Block}

The South China Block is composed of the two major elements, the Yangtze Craton and the Cathaysia Block, which is separated by the XuefengJiuling Orogen (also known Jiangnan Orogen). The orogen is considered as a continent-continent collision between Yangtze Craton and Cathaysia Block in the Neoproterozoic (e.g., Zheng et al., 2013; Zhao, 2015).

The Sichuan Basin and the eastern part of the Yangtze Craton show consistently fast $\mathrm{P}$ wavespeeds beneath the base of the crust, from $50 \mathrm{~km}$ down to more than $75 \mathrm{~km}$ despite limited resolution at the eastern edge of this zone. Such high velocities in the stable and old part of the Yangtze craton are a featue in a wide range of different studies (e.g., Hearn et al., 2004; Liang et al., 2004; Pei et al., 2007; Wang et al., 2013b).

There is a strong contrast between the fast western part of the Cathaysia belt and the slower eastern part just below the crust at $45 \mathrm{~km}$, but this is much less pronounced at greater depth. The low velocities for both $\mathrm{P}$ and $\mathrm{S}$ beneath Cathaysia Block can extend downward to the mantle transition as revealed by teleseismic body wave tomography (Zhao et al., 2012). The contrasts are likely to be linked to the influence of the Xuefeng-Jiuling Orogen and magmatic activities in middle Neoproterozoic inferred from the wide distributions of magmatic rocks (e.g., Zhang and Zheng, 2013). Zhao et al. (2012) consider that the structures might relate to mantle convection and partial melting due to subduction of the Paleo-Pacific plate in the late Mesozoic, slightly earlier than the middle Neoproterozoic magmatic activities in Cathaysia Block. 


\section{Conclusions}

We have constructed a $\mathrm{P}$ wave velocity model for the uppermost mantle across eastern China from travel-time tomography using Pn arrivals. We constructed an initial 3-D P wavespeed model by combining CRUST1.0 with a P model derived from SL2013sv (Schaeffer and Lebedev, 2013). This combination provides a good representation of the major features of lithospheric structure across the region. The subsequent inversion using the FMTOMO approach converges very rapidly, introducing more localised variations. Across most of the region we are able to achieve resolution of $2^{\circ} \times 2^{\circ}$ or better down to a depth of $75 \mathrm{~km}$, with some loss of resolution below. Although there are events, the low density of seismic stations in Mongolia and southern Siberia limits resolution in this area. We have created new model for the entire region by incorporating the inverted Pn and crustal velocities into a consistent 3-D framework, and this provides a further potential improvement in the accuracy of earthquake location using the nonliner 3-D location scheme of de Kool and Kennett (2014).

The $\mathrm{P}$ velocity structure in the uppermost mantle of east Asia is complex with significant substructure in the cratonic regions. The reliability of the results is confirmed by an alternative inversion starting from the LITHO1.0 model of Pasyanos et al. (2014) that is presented in the Supplementary material.

The central portion of the North China craton is imaged with particularly slow $\mathrm{P}$ wavespeeds, whilst most of the neighbouring Ordos block is fast. Fast $\mathrm{P}$ wavespeeds extend through much of the uppermost mantle beneath eastern Central Asian Orogen and northeast China, probably associated with cratonic fragments, and beneath the Korean peninsula. In the south, the Sichuan Block and the western Yangtze craton show rather fast $\mathrm{P}$ wavespeeds. The Tanlu fault system appears to cut through the crust into the mantle, with marked slow $\mathrm{P}$ wavespeed at its southern end.

\section{Acknowledgements}

This work has been carried out at the Research School of Earth Sciences, The Australian National University. The research was supported in large part by the China Scholarship Council (Grant no. 201404910184) and the National Natural Science Foundation of China (Grant no. 41474105), with additional support from the AuScope AuSREM project. 
The waveform data for the Chinese permanent stations was retrieved from Data Management Centre of China National Seismic Network at Institute of Geophysics (IGP), China Earthquake Administration (SEISDMC, doi:10.7914/SN/CB) and IRIS Data Management Center. Bulletin data was fetched from the China Earthquake Data Center (CEDC, data.earthquake.cn) and International Seismological Centre (www.isc.ac.uk).

\section{References}

Buehler, J. S., Shearer, P. M., 2014. Anisotropy and Vp/Vs in the uppermost mantle beneath the western United States from joint analysis of Pn and Sn phases. J. Geophys. Res. - Solid Earth, 119(2), 1200-1219.

de Kool, M., Kennett, B. L. N., 2014. Practical earthquake location on a continental scale in australia using the AuSREM 3D velocity model. Bull. Seism. Soc. Am. 104 (6), 2755-2767.

de Kool, M., Rawlinson, N., Sambridge, M., 2006. A practical grid-based method for tracking multiple refraction and reflection phases in three-dimensional heterogeneous media. Geophys. J. Int. 167 (1), 253-270.

Didenko, A. N., Kaplun, V. B., Malyshev, Y. F., Shevchenko, B. F., 2010. Lithospheric structure and Mesozoic geodynamics of the eastern central Asian orogen. Russian Geol. Geophys. 51 (5), 492-506.

Dong, Y. P., Liu, X. M., Zhang, G. W., Chen, Q., Zhang, X. N., Li, W., Yang, C., 2012. Triassic diorites and granitoids in the Foping area: Constraints on the conversion from subduction to collision in the Qinling orogen, China. J. Asian Earth Sci. 47, 123-142.

Dong, H., Wei, W., Ye, G., Jin, S., Jones, A. G., Jing, J., Zhang, L., Xie, C., Zhang, F., Wang H., 2014. Three-dimensional electrical structure of the crust and upper mantle in Ordos Block and adjacent area: Evidence of regional lithospheric modification. Geochem. Geophys. Geosyst., 15(6), 24142425.

Fichtner, A., Kennett, B. L. N., Igel, H., Bunge, H. P., 2009. Full seismic waveform tomography for upper-mantle structure in the Australasian region using adjoint methods. Geophys. J. Int. 179 (3), 1703-1725.

Glebovitsky, V. A., Khil'tova, V. Y., Kozakov, I. K., 2008. Tectonics of the Siberian craton: Interpretation of geological, geophysical, geochronological, and isotopic geochemical data. Geotectonics 42 (1), 8-20.

Guo, Z., Chen, Y. J., Ning, J. Y., Feng, Y. G., Grand, S. P., Niu, F. L., Kawakatsu, H., Tanaka, S., Obayashi, M., Ni, J., 2015. High resolution 3-D crustal structure beneath NE China from joint inversion of ambient noise and receiver functions using NECESS array data. Earth Planet. Sci. Lett, 416, 1-11.

Hearn, T. M., Wang, S. Y., Ni, J. F., Xu, Z. H., Yu, Y. X., Zhang, X. D., 2004. Uppermost mantle velocities beneath China and surrounding regions. J. Geophys. Res. - Solid Earth 109 (B11).

Hearn, T. M., Wang, S. Y., Pei, S. P., Xu, Z. H., Ni, J. F., Yu, Y. X., 2008. Seismic amplitude tomography for crustal attenuation beneath China. Geophys. J. Int. 174 (1), $223-234$. 
Hong, Tae-Kyung and Kang, Tae-Seob., 2009. Pn travel-time tomography of the paleocontinental-collision and rifting zone around Korea and Japan. Bull. Seism. Soc. Am. 99(1), 416-421.

Huang, J. L., Zhao, D. P., 2009. Seismic imaging of the crust and upper mantle under Beijing and surrounding regions. Phys. Earth Planet. Inter. 173 (3-4), 330-348.

Jiang G., Zhang G., Zhao D., Lü Q., Li H., Li X., Mantle dynamics and Cretaceous magmatism in east-central China: Insight from teleseismic tomograms, Tectonophysics, 664, 256-268.

Kaiho, Y., Kennett, B. L. N., 2000. Three-dimensional seismic structure beneath the Australasian region from refracted wave observations. Geophys. J. Int. 142 (3), 651668.

Kennett, B. L. N., Engdahl, E. R., Buland, R., 1995. Constraints on seismic velocities in the Earth from travel-times. Geophys. J. Int. 122 (1), 108-124.

Kennett, B. L. N., Fichtner, A., Fishwick, S., Yoshizawa, K., 2013. Australian seismological reference model (AuSREM): mantle component. Geophys. J. Int. 192 (2), 871-887.

Koulakov, I., Bushenkova, N., 2010. Upper mantle structure beneath the Siberian craton and surrounding areas based on regional tomographic inversion of $\mathrm{P}$ and $\mathrm{PP}$ travel times. Tectonophysics 486 (1-4), 81-100.

Kulakov, I. Y., 2008. Upper mantle structure beneath southern Siberia and Mongolia, from regional seismic tomography. Russian Geol. Geophys. 49 (3), 187-196.

Laske, G., Masters, G., Ma, Z., Pasyanos, M., 2013. Update on CRUST1.0 - a 1-degree global model of Earths crust. In: Geophys. Res. Abstracts. Vol. 15. p. 2658.

Legendre, C. P., Chen, Q. F., Zhao, L., 2014. Lithospheric structure beneath the East China Sea revealed by Rayleigh-wave phase velocities. J. Asian Earth Sci., 96, 213-225.

Lei, J. S., 2012. Upper-mantle tomography and dynamics beneath the north China craton. J. Geophys. Res. - Solid Earth 117 (B06313).

Lei, J. S., Zhao, D. P., 2005. P-wave tomography and origin of the Changbai intraplate volcano in northeast Asia. Tectonophysics 397 (3-4), 281-295.

Leveque, J. J., Rivera, L., Wittlinger, G., 1993. On the use of the checkerboard test to assess the resolution of tomographic inversions. Geophys. J. Int. 115 (1), 313-318.

Li, S. L., Mooney, W. D., Fan, J. C., 2006a. Crustal structure of mainland China from deep seismic sounding data. Tectonophysics 420 (1-2), 239-252.

Li, S. Z., Kusky, T. M., Wang, L., Zhang, G. W., Lai, S. C., Liu, X. C., Dong, S. W., Zhao, G. C., 2007. Collision leading to multiple-stage large-scale extrusion in the Qinling orogen: Insights from the Mianlue suture. Gondwana Res. 12 (1-2), 121-143.

Li, S. Z., Zhao, G. C., Wilde, S. A., Zhang, J. A., Sun, M., Zhang, G. W., Dai, L. M., 2010. Deformation history of the Hengshan-Wutai-Fuping Complexes: Implications for the evolution of the Trans-North China Orogen. Gondwana Res., 18(4), 611-631.

Li, Y. H., Gao, M. T., Wu, Q. J., 2014. Crustal thickness map of the Chinese mainland from teleseismic receiver functions. Tectonophysics $611,51-60$.

Li, Z. W., Hao, T. Y., Xu, Y., 2011. Uppermost mantle structure of the north China craton: Constraints from interstation Pn travel time difference tomography. Chinese Science Bulletin 56 (16), 1691-1698.

Li, Z. W., Xu, Y., Hao, T. Y., Liu, J. S., Zhang, L., 2006b. Seismic tomography and velocity structure in the crust and upper mantle around Bohai sea area. Chinese J. 
Geophys. - Chinese Edition 49 (3), 797-804.

Liang, C. T., Song, X. D., Huang, J. L., 2004. Tomographic inversion of Pn travel times in China. J. Geophys. Res. - Solid Earth 109 (B11).

Liu, B. J., Feng, S. Y., Ji, J. F., Shi, J. H., Tan, Y. L., Li, Y. Q., 2015. Fine lithosphere structure beneath the middle-southern segment of the Tan-Lu fault zone. Chinese J. Geophys. - Chinese Edition, 58 (5), 1610-1621.

Panning M. P., Cao, A., Kim, A., Romanowicz, B. A., 2012. Non-linear 3-D Born shear waveform tomography in Southeast Asia. Geophys. J. Int., 190(1): 463-475.

Pasyanos, M.E., Masters, T.G., Laske, G., and Ma, Z., 2014. LITHO1.0: An updated crust and lithospheric model of the Earth. J. Geophys. Res., 119 (3), 2153-2173.

Pei, S. P., Zhao, J. M., Sun, Y. S., Xu, Z. H., Wang, S. Y., Liu, H. B., Rowe, C. A., Toksoz, M. N., Gao, X., 2007. Upper mantle seismic velocities and anisotropy in China determined through Pn and Sn tomography. J. Geophys. Res. - Solid Earth 112 (B5).

Ranasinghe, N. R., Gallegos, A. C., Trujillo, A. R., Blanchette, A. R., Sandvol, E. A., Ni, J., Hearn, T. M., Tang, Y. C., Grand, S. P., Niu, F. L., Chen, Y. S. J., Ning, J. Y., Kawakatsu, H., Tanaka, S., Obayashi, M., 2015. Lg attenuation in northeast China using NECESS array data. Geophys. J. Int. 200 (1), 67-76.

Rawlinson, N., Urvoy, M., 2006. Simultaneous inversion of active and passive source datasets for 3-D seismic structure with application to Tasmania. Geophys. Res. Lett. 33 (24).

Ritzwoller, M. H., Barmin, M. P., Villasenor, A., Levshin, A. L., Engdahl, E. R., 2002. Pn and Sn tomography across Eurasia to improve seismic event locations. Tectonophysics $358(1-4), 39-55$.

Sambridge, M. S., Kennett, B. L. N., 2001. Seismic event location: Nonlinear inversion using a neighbourhood algorithm. Pure Applied Geophys. 158 (1-2), 241-257.

Schaeffer, A. J., Lebedev, S., 2013. Global shear speed structure of the upper mantle and transition zone. Geophys. J. Int. 194 (1), 417-449.

Simmons, N. A., Myers, S. C., Johannesson, G., Matzel, E., 2012. Llnl-g3dv3: Global P wave tomography model for improved regional and teleseismic travel time prediction. J. Geophys. Res. - Solid Earth 117.

Sun, Y. S., Toksoz, M. N., 2006. Crustal structure of China and surrounding regions from P wave traveltime tomography. J. Geophys. Res. - Solid Earth 111 (B3).

Suo, K., Zhang, G. B., Jiang, G. M., Xu, Y., 2015. 3-D density distribution of the crust and upper mantle beneath Northeast China by joint inversion of gravity and seismic data. Chinese J Geophys-Ch, 58 (7), 2436-2444.

Tang, Y. C., Obayashi, M., Niu, F. L., Grand, S. P., Chen, Y. J., Kawakatsu, H., Tanaka, S., Ning, J. Y., Ni, J. F., 2014. Changbaishan volcanism in northeast China linked to subduction-induced mantle upwelling. Nature Geoscience 7 (6), 470-475.

Tian, Y., Zhao, D. P., Sun, R. M., Teng, J. W., 2009. Seismic imaging of the crust and upper mantle beneath the north China craton. Phys. Earth Planet. Inter. 172 (3-4), $169-182$.

Wang, J., Zhao, D. P., Yao, Z. X., 2013a. Crustal and uppermost mantle structure and seismotectonics of north China craton. Tectonophysics 582, 177-187.

Wang, S. Y., Niu, F. L., Zhang, G. M., 2013b. Velocity structure of the uppermost mantle beneath east Asia from Pn tomography and its dynamic implications. J. Geophys. Res. - Solid Earth 118 (1), 290-301. 
Xu, Y., Li, Z. W., Hao, T. Y., Lu, J. H., Liu, J. S., 2007. Pn wave velocity and anisotropy in the northeastern South China Sea and adjacent region. Chinese J. Geophys. Chinese Edition 50 (5), 1473-1479.

Xu, Y., Li, Z. W., Liu, J. S., Hao, T. Y., 2008a. Pn wave velocity and anisotropy in the Yellow Sea and adjacent region. Chinese J. Geophys. -Chinese Edition 51 (5), 1444-1450.

Zhao, L., Allen, R. M., Zheng, T. Y., Hung, S. H., 2009. Reactivation of an Archean craton: Constraints from P- and S-wave tomography in North China. Geophys Res Lett, 36, L17306.

Zhao, L., Allen, R. M., Zheng, T., Zhu, R., 2012. High-resolution body wave tomography models of the upper mantle beneath eastern China and the adjacent areas. Geochem Geophy Geosys, 13(6), Q06007.

Zhao, L. F., Xie, X. B., Wang, W. M., Zhang, J. H., Yao, Z. X., 2013. Crustal Lg attenuation within the north China craton and its surrounding regions. Geophys. J. Int. 195 (1), 513-531.

Zhang, S.-B., Zheng, Y.-F., 2013. Formation and evolution of Precambrian continental lithosphere in South China. Gondwana Research 23, 1241-1260

Zhao, G., 2015, Jiangnan Orogen in South China: Developing from divergent double subduction. Gondwana Research. 27, 1173-1180.

Zheng, Y. F., Xiao, W. J., Zhao, G. C., 2013. Introduction to tectonics of China. Gondwana Research 23 (4), 1189-1206.

Zhu, R. X., Zheng, T. Y., 2009. Destruction geodynamics of the north China craton and its Paleoproterozoic plate tectonics. Chinese Science Bulletin 54 (19), 3354-3366.

\section{A. Vertical sections through the initial model}

We here present cross-sections through the initial $\mathrm{P}$ wave model at constant longitude and latitude to allow comparisons with the results after inversion shown in Figures 10 and 11. 


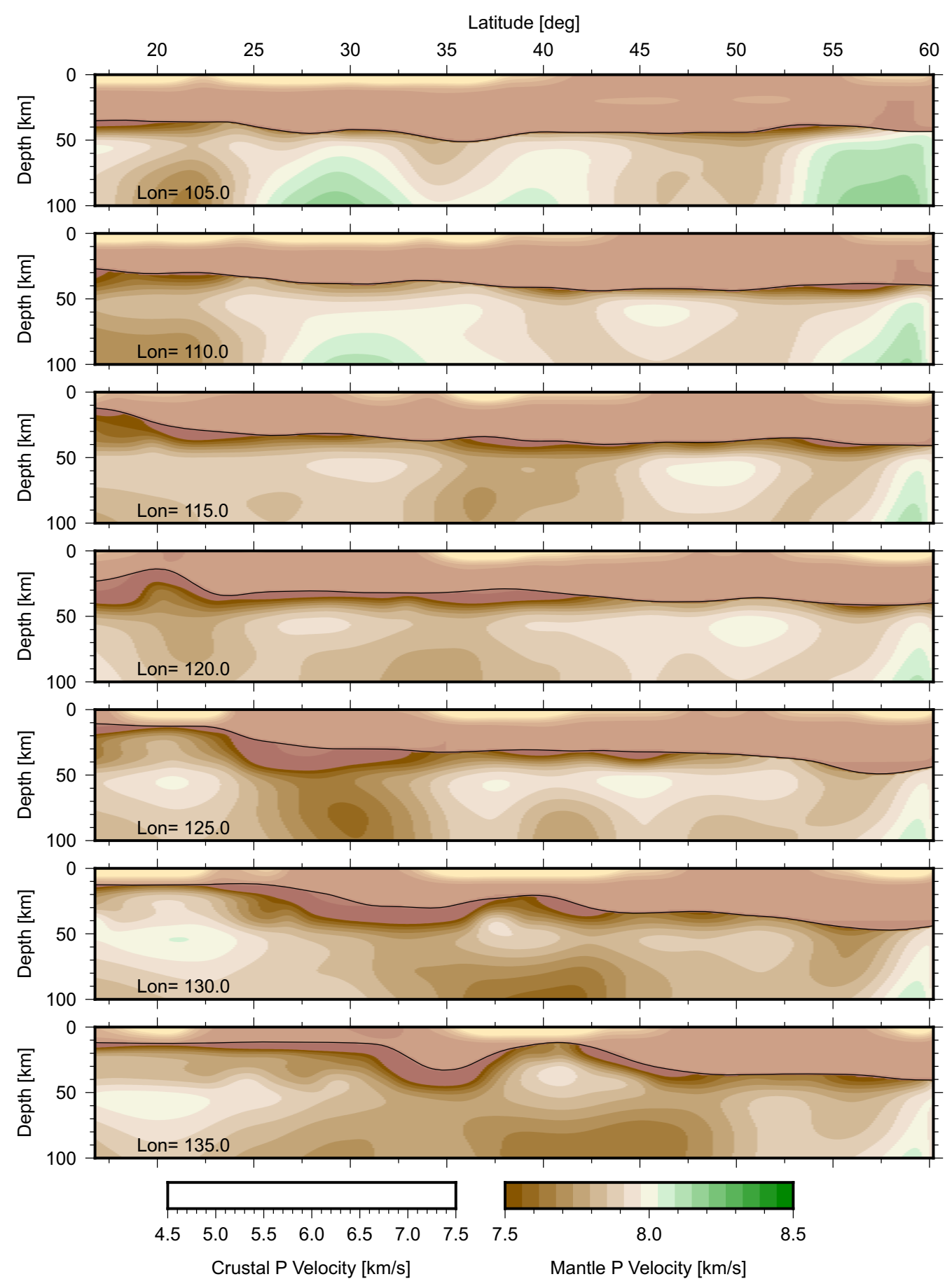

Figure A1: Sections through the initial Pn wavespeed for longitudes between $105^{\circ}$ and $135^{\circ}$ in step of $5^{\circ}$. The sections are displayed as the absolute velocities. Separate color schemes are used for the crust and mantle $\mathbf{B} \Phi$ allow detail to be seen. 


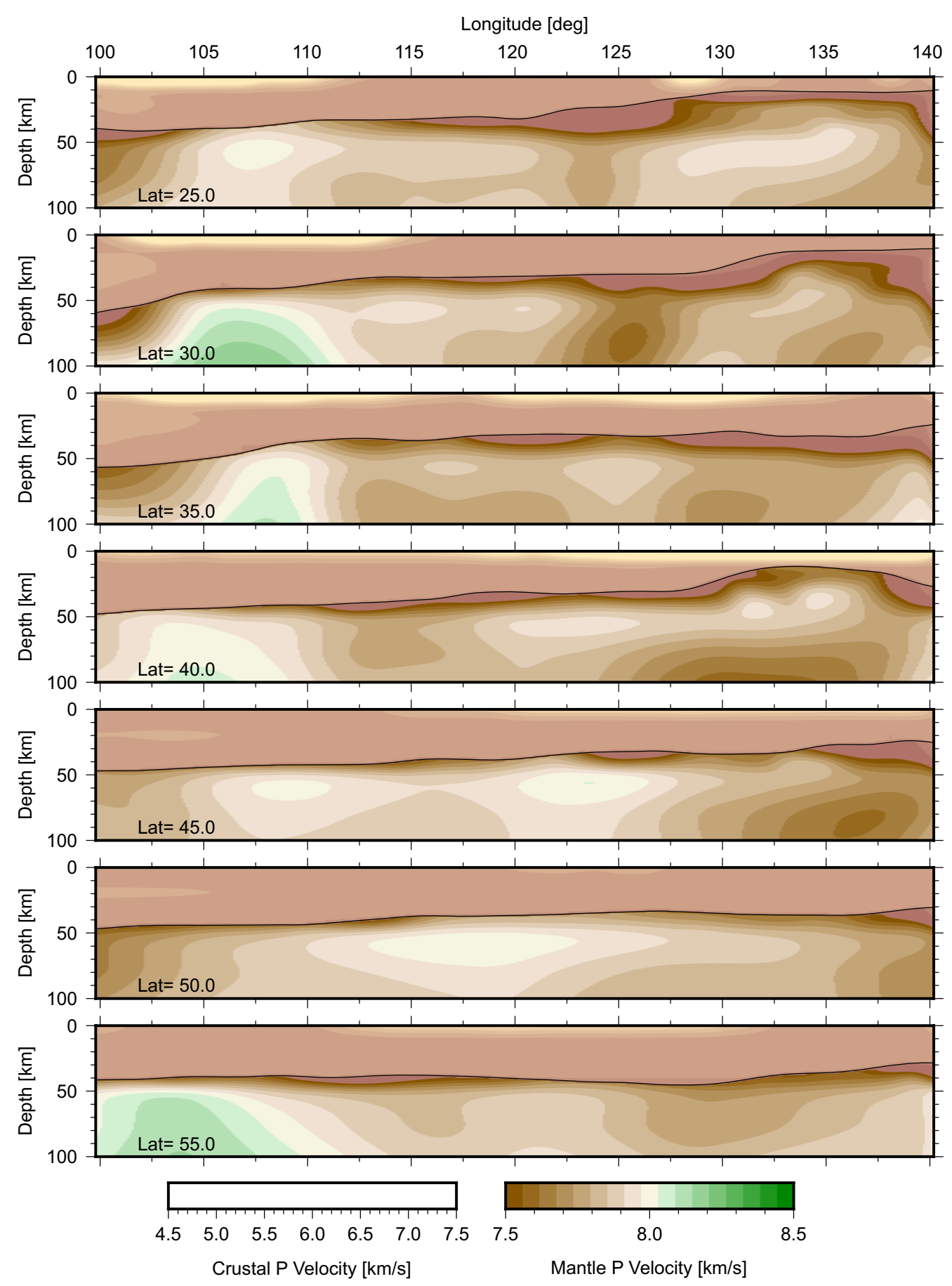

Figure A2: Sections through the initial Pn wavespeed for latitudes between $25^{\circ}$ and $55^{\circ}$ in step of $5^{\circ}$. The sections are displayed as the absolute velocities. Separate color schemes are used for the crust and mantle 32 allow detail to be seen. 